\title{
Polar Phonon Behaviour in Polycrystalline Bi-Doped Strontium Titanate Thin Films
}

\author{
Alexander Tkach ${ }^{1}\left(\mathbb{D}\right.$, Olena Okhay $\left.{ }^{2, *} \mathbb{(}\right)$, Dmitry Nuzhnyy ${ }^{3}$, Jan Petzelt ${ }^{3}\left(\mathbb{D}\right.$ and Paula M. Vilarinho ${ }^{1}$ \\ 1 Department of Materials and Ceramic Engineering, CICECO-Aveiro Institute of Materials, \\ University of Aveiro, 3810-193 Aveiro, Portugal; atkach@ua.pt (A.T.); paula.vilarinho@ua.pt (P.M.V.) \\ 2 TEMA-Centre for Mechanical Technology and Automation, Department of Mechanical Engineering, \\ University of Aveiro, 3810-193 Aveiro, Portugal \\ 3 Institute of Physics of the Czech Academy of Sciences, Na Slovance 2, 18221 Prague, Czech Republic; \\ nuzhnyj@fzu.cz (D.N.); petzelt@fzu.cz (J.P.) \\ * Correspondence: olena@ua.pt
}

Citation: Tkach, A.; Okhay, O.;

Nuzhnyy, D.; Petzelt, J.; Vilarinho, P.M. Polar Phonon Behaviour in Polycrystalline Bi-Doped Strontium Titanate Thin Films. Materials 2021, 14, 6414. https://doi.org/10.3390/ ma14216414

Academic Editor: George Kioseoglou

Received: 20 September 2021

Accepted: 21 October 2021

Published: 26 October 2021

Publisher's Note: MDPI stays neutral with regard to jurisdictional claims in published maps and institutional affiliations.

Copyright: (c) 2021 by the authors. Licensee MDPI, Basel, Switzerland. This article is an open access article distributed under the terms and conditions of the Creative Commons Attribution (CC BY) license (https:// creativecommons.org/licenses/by/ $4.0 /)$.

\begin{abstract}
Strontium titanate-based materials with ferroelectric or relaxor-like properties have drawn vast attention as polar dielectrics for electronics and telecommunications. Here, we study the lattice dynamics in sol-gel-derived $\mathrm{Sr}_{1-1.5 \mathrm{x}} \mathrm{Bi}_{\mathrm{x}} \mathrm{TiO}_{3}$ thin films with $\mathrm{x}=0.0053$ and 0.167 , deposited on $\mathrm{Al}_{2} \mathrm{O}_{3}$ substrates, using a variable-temperature far-infrared spectroscopy in a transmittance mode. $\mathrm{Bi}$ doping, known to induce a low-frequency dielectric relaxation in $\mathrm{SrTiO}_{3}$ (ST) ceramics and films, due to off-centre dopant ion displacements generating electric dipoles, is shown to affect the polar phonon behaviour of thin films. We show that in weakly Bi-doped films, the low-frequency polar TO1 mode softens on cooling but less than in undoped ST. In heavily Bi-doped ST films, this mode displays no significant frequency variation with temperature from 300 to $10 \mathrm{~K}$. The polar phonon behaviour of polycrystalline Bi-doped ST thin films is comparable with that of Bi-doped ST ceramics, which exhibit dielectric relaxations and harden soft-mode behaviour instead of the ferroelectric phase transition.
\end{abstract}

Keywords: perovskites; polar dielectrics; thin films; infrared spectroscopy

\section{Introduction}

Perovskite-structured $\mathrm{SrTiO}_{3}$ (ST) stands out as an incipient ferroelectric with dielectric permittivity increasing continuously on cooling due to the polar-mode softening but without a ferroelectric phase transition [1-5]. Incipient ferroelectrics exhibit small values of the dissipation factor, tan $\delta$, and strong dependence of the real part of the dielectric permittivity, $\varepsilon^{\prime}$, on electric field, which makes them attractive for applications in tunable electronic components [6,7]. Although $\mathrm{SrTiO}_{3}$ has been studied for decades, its practical importance in terms of applications, in particular in the thin-film form, to respond to the most recent requirements for miniaturization from the microelectronics industry, fully justify the renewed interests in this material [8].

The lattice dynamics is of central importance for understanding the structural properties of materials. The phonon behaviour in ST bulk was studied using far-infrared (IR) spectroscopy [9], neutron scattering [10], Raman scattering [2] and hyper-Raman scattering [11]. Besides the cubic-to-tetragonal (antiferrodistortive) phase transition, observed in ST single crystals at about $110 \mathrm{~K}$, due to the instability of the zone-corner soft mode [12], the soft-mode behaviour has also been shown to be the basis for the dielectric nonlinearity in ST. The zone-centre soft-mode phonon was reported to increase its frequency with applied electric field [2]. This indicates that the mechanism for the reduction of the dielectric permittivity $\varepsilon^{\prime}$ under applied field is due to the hardening of the soft mode [2], which arises from the anharmonic restoring forces on Ti ions when displaced from their equilibrium positions [13]. 
According to reports on the lattice dynamics of ST films, the soft mode of the films is usually much harder than that in the bulk materials at low temperature [14-19]. Correspondingly, the phonon contribution to the low-temperature dielectric permittivity is strongly suppressed in ST films compared to bulk ST. For epitaxial films deposited by pulsed laser deposition (PLD), it was explained by influence of some specific local polar regions occurring in ST thin films during the deposition process [15]. For polycrystalline films, porosity and eccentricity of the grain boundaries are suggested as the main reasons for such behaviour [18]. Sirenko et al. reported that at high temperatures the soft-mode frequency in the film and the bulk are close at zero electric field, indicating that either the density of the local polar regions is low or the polarization of these regions is weak or small [15]. However, whereas the electric-field hardening of the soft mode vanishes in ST crystals above $\mathrm{T} \approx 80 \mathrm{~K}$ [20], it persists in ST thin films until high temperatures. This fact was attributed to the polarization by the electric field of the easily polarisable local regions around oxygen vacancies, which are expected to increase the dielectric loss in thin films [15]. At the same time, Ostapchuk et al. reported that in contrast to polycrystalline ST films, a $300 \mathrm{~nm}$ thick ST film, quasiepitaxially grown on a (0001) sapphire substrate with a perfect (111) orientation, displays a ferroelectric phase transition near $125 \mathrm{~K}$ induced in the film plane by a tensile residual stress [18].

Among ST-based compounds [5], Bi-doped ST solid solutions have been intensively studied as for dielectric [21,22] as for resistance-switching memory [23] and thermoelectric applications [24]. In $\mathrm{Sr}_{1-1.5 \mathrm{x}} \mathrm{Bi}_{x} \mathrm{TiO}_{3}$, ceramics displacements of $\mathrm{Bi}^{3+}$ ions on cuboctahedral Sr sites were reported to generate local dipole moments that induce dielectric relaxations but harden the ST polar soft mode [25-27]. As a result, these ceramics feature no ferroelectric phase transition but relaxations at frequencies up to the THz range [27]. Similar to the Bi-doped ST ceramics, Bi-doped ST thin films exhibit dielectric relaxations, which have also been attributed to a positional disorder of $\mathrm{Bi}^{3+}$ on $\mathrm{Sr}$ sites [21,28].

Although the dielectric response of Bi-doped ST films on platinized Si [21,28-34] and polar phonon behaviour of undoped ST films on $\mathrm{Al}_{2} \mathrm{O}_{3}$ substrates have been investigated $[18,35,36]$, so far no research has been undertaken of the lattice dynamics in Bi-doped ST thin films, particularly as a function of temperature. To fill this gap and determine the effect of Bi doping on the polar phonon behaviour of ST thin films, we performed a variable-temperature far-infrared spectroscopy study of sol-gel-derived $\mathrm{Sr}_{1-1.5 \mathrm{x}} \mathrm{Bi}_{\mathrm{x}} \mathrm{TiO}_{3}$ thin films with $\mathrm{x}=0.0053$ and 0.167 , deposited on $\mathrm{Al}_{2} \mathrm{O}_{3}$ substrates, since these substrates were found to not constrain the soft mode of undoped polycrystalline ST films [36].

\section{Materials and Methods}

For this study, we selected $\mathrm{Sr}_{1-1.5 \mathrm{x}} \mathrm{Bi}_{\mathrm{x}} \mathrm{TiO}_{3}$ thin films with $\mathrm{x}=0.0053$ and 0.167 prepared using the sol-gel method, which has been demonstrated to yield a single perovskite phase [21,29]. For the preparation of the sols with a concentration of about $0.2 \mathrm{M}$, according to the schematic diagram shown in Figure 1, the following reagents were used in proportions depending on the film's composition: strontium acetate $\mathrm{C}_{4} \mathrm{H}_{6} \mathrm{O}_{4} \mathrm{Sr}(98 \%$, abcr $\mathrm{GmbH}$, Karlsruhe, Germany), tetra-n-butyl orthotitanate $\mathrm{C}_{16} \mathrm{H}_{36} \mathrm{O}_{4} \mathrm{Ti}(98 \%$, Merck KGaA, Darmstadt, Germany), bismuth acetate $\mathrm{C}_{6} \mathrm{H}_{9} \mathrm{O}_{6} \mathrm{Bi}(99 \%$, abcr GmbH, Karlsruhe, Germany), acetic acid $\mathrm{C}_{2} \mathrm{H}_{4} \mathrm{O}_{2}\left(99.8 \%\right.$, Merck KGaA, Darmstadt, Germany), 1,2-propanediol $\mathrm{C}_{3} \mathrm{H}_{8} \mathrm{O}_{2}$ (99.5\%, Riedel-de Haën, Seelze, Germany) and absolute ethanol $\mathrm{C}_{2} \mathrm{H}_{6} \mathrm{O}(99.8 \%$, Merck KGaA, Darmstadt, Germany). Using the previously prepared precursor solutions, layers were deposited on the substrates by spin-coating at $4000 \mathrm{rpm}$ for $30 \mathrm{~s}$, using the spin coater KW-4A (Chemat Technology, Los Angeles, CA, USA). Before utilisation, the substrates were cleaned in boiling ethanol and dried on a hot plate. Subsequently, the films (substrate with the wet layer) were heated on a hot plate at $350^{\circ} \mathrm{C}$ for $\sim 1 \mathrm{~min}$. This step was repeated after each spinning to ensure complete removal of the volatile species between each layer. After the deposition of the required number of layers (here 15 layers), they were annealed in air at $750{ }^{\circ} \mathrm{C}$ for $60 \mathrm{~min}$ with heating/cooling rate of $5{ }^{\circ} \mathrm{C} / \mathrm{min}$, resulting in the films with final thickness of about $450 \mathrm{~nm}$. All Bi-doped ST films were deposited on double-side 
polished $\mathrm{Al}_{2} \mathrm{O}_{3}$ sapphire single crystals (Crystal $\mathrm{GmbH}$., Berlin, Germany) to study them by IR spectroscopy in the transmittance mode. Similarly prepared undoped ST films were also studied for comparison.

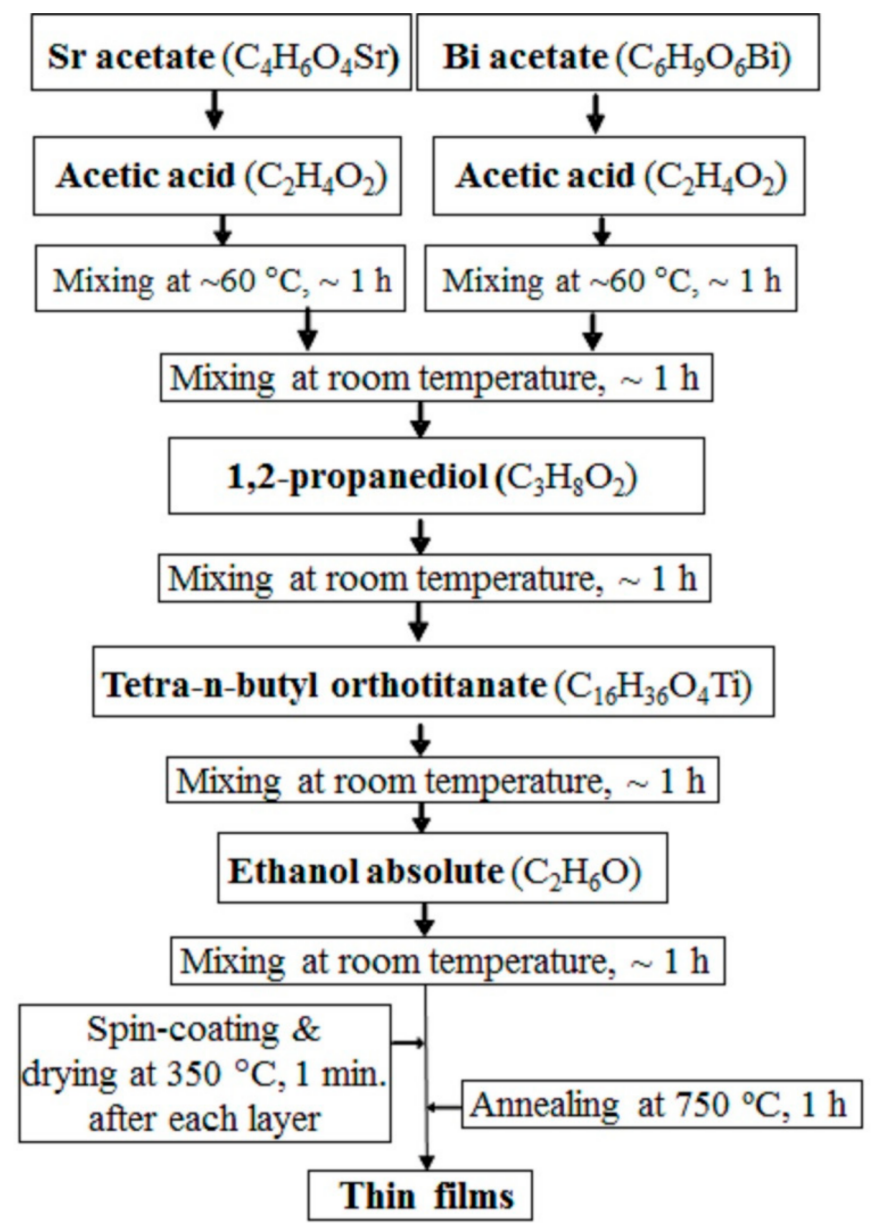

Figure 1. Schematic diagram of the preparation process for $\mathrm{Sr}_{1-1.5 \mathrm{x}} \mathrm{Bi}_{\mathrm{x}} \mathrm{TiO}_{3}$ thin films with $\mathrm{x}=0.0053$ and 0.167 deposited on $\mathrm{Al}_{2} \mathrm{O}_{3}$ substrates.

Compositional analysis of the films was done using an energy-dispersive spectroscopy (EDS) system (QUANTAX 75/80, Bruker, Ettlingen, Germany) in the top-view geometry under the accelerating voltage of $15 \mathrm{kV}$ of a scanning electron microscope (Hitachi TM4000Plus, Tokyo, Japan). The thin-film crystal phase was analysed at room temperature in out-of-plane geometry using an X-ray diffractometer (Rigaku D/teX Ultra 250, Tokyo, Japan). The data were recorded in $0.02^{\circ}$ step mode with a scanning rate of $1^{\circ} / \mathrm{min}$ from $20^{\circ}$ to $80^{\circ}$ using $\mathrm{Cu}$ Ka radiation (at $40 \mathrm{kV}, 30 \mathrm{~mA}$ ). Far-infrared transmittance was measured on the interferometer (Bruker IFS 113v, Ettlingen, Germany) in the $\sim 20-250 \mathrm{~cm}^{-1}$ range with a resolution of $0.5 \mathrm{~cm}^{-1}$ in unpolarized light. Transmission geometry was chosen because it allows one to determine the TO1 mode parameters unambiguously in the case of a highly reflecting ST-based system. The spectrometer was equipped with a liquid-Hecooled bolometer used as the detector and polyethylene beam splitters of 6,50 and $75 \mu \mathrm{m}$ thicknesses. The samples were mounted in a helium continuous-flow Optistat CF cryostat (Oxford Instruments, Oxford, UK) with polyethylene windows and cooled down to $10 \mathrm{~K}$. The incident beam was normal to the sample surface, so that only the in-plane component of the dielectric response was probed. 


\section{Results and Discussion}

EDS analysis of $\mathrm{Sr}_{1-1.5 \mathrm{x}} \mathrm{Bi}_{\mathrm{x}} \mathrm{TiO}_{3}$ thin films, presented in Figure $2 \mathrm{a}$, clearly displays the Bi peak intensity increase with $x$ value and simultaneous decrease of the Sr to Ti peak intensity ratio. Moreover, according to the spectra quantification, the bismuth concentrations in both $\mathrm{Sr}_{1-1.5 \mathrm{x}} \mathrm{Bi}_{\mathrm{x}} \mathrm{TiO}_{3}$ thin films with $\mathrm{x}=0.0053$ and 0.167 are very close to the nominal ones. Overall, estimated elemental contents indicate the proximity of both film compositions to the nominal ones within error bars.

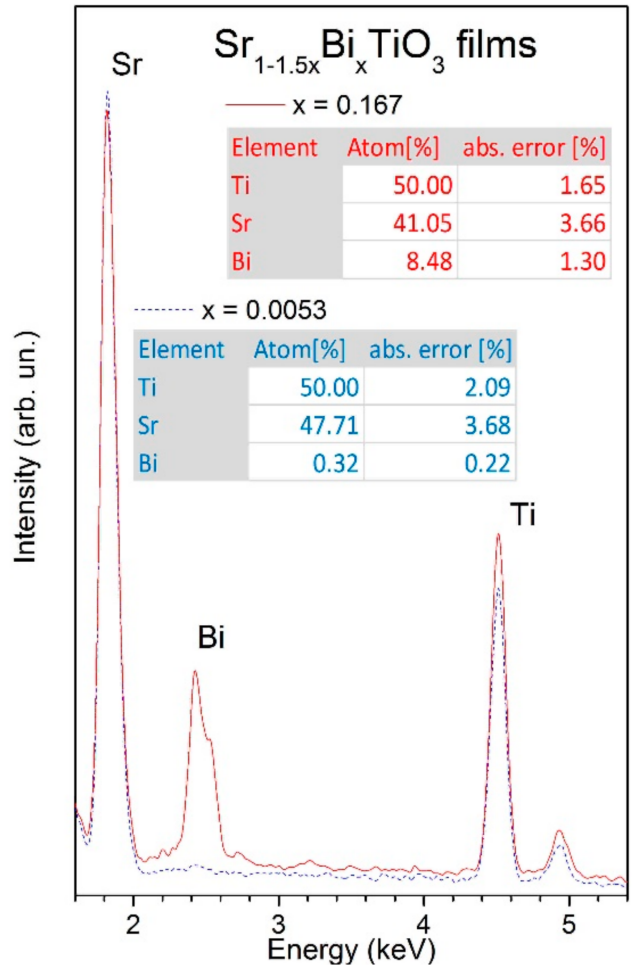

(a)

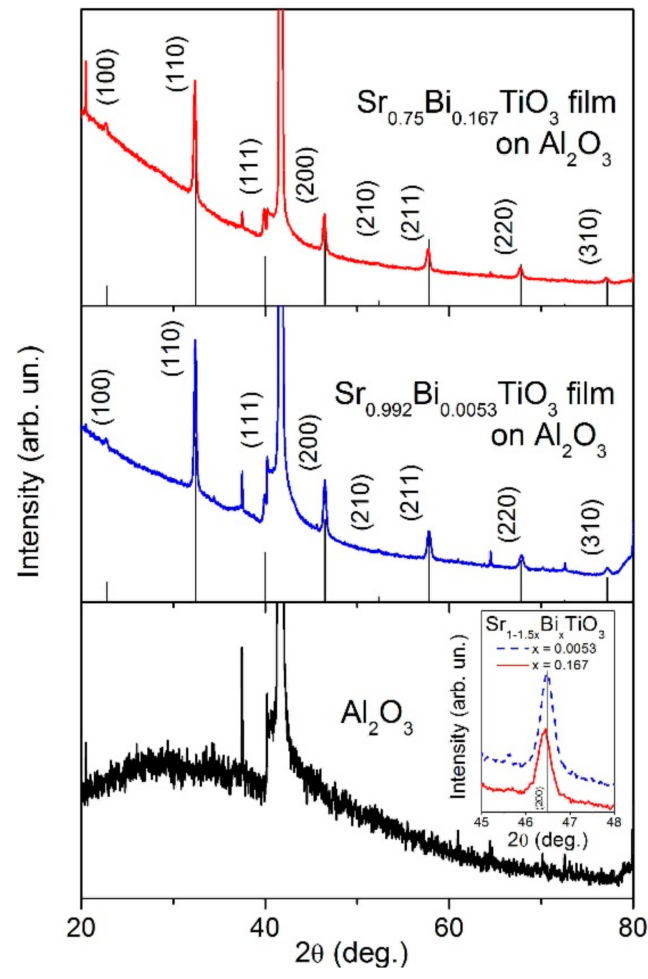

(b)

Figure 2. Energy-dispersive spectra and their elemental quantification results (a) as well as X-ray diffraction profiles (b) for $\mathrm{Sr}_{1-1.5 \mathrm{x}} \mathrm{Bi}_{\mathrm{x}} \mathrm{TiO}_{3}$ thin films with $\mathrm{x}=0.0053$ and 0.167 deposited on $\mathrm{Al}_{2} \mathrm{O}_{3}$ substrates. The $\mathrm{X}$-ray diffraction profile for bare $\mathrm{Al}_{2} \mathrm{O}_{3}$ substrate is presented in the bottom panel of $(\mathbf{b})$. The reflections related to the perovskite structure of $\mathrm{SrTiO}_{3}$ (PDF\#35-0734) with corresponding indexes are also shown in (b), as well as magnified view at reflection (200) as inset in the bottom panel of (b).

X-ray diffraction (XRD) profiles of Bi-doped $\mathrm{ST}$ films on $\mathrm{Al}_{2} \mathrm{O}_{3}$ substrates are shown in Figure $2 \mathrm{~b}$, revealing only peaks related to the perovskite structure of $\mathrm{SrTiO}_{3}(\mathrm{PDF} 335-0734)$ and those from bare $\mathrm{Al}_{2} \mathrm{O}_{3}$ substrate, also displayed in Figure $2 \mathrm{~b}$. The only difference between the weakly and heavily Bi-doped ST films is a slight shift of the XRD peaks toward lower $2 \theta$ values with Bi content, implying the lattice parameter increase. Such behaviour is in agreement with that observed in Bi-doped ST ceramics [37] and explained by the slightly larger ionic size of $\mathrm{Bi}^{3+}$ compared to that of $\mathrm{Sr}^{2+}$ at coordination number of 12 [22] as well as by the larger size of $\mathrm{Sr}$ vacancies present in $\mathrm{Sr}_{1-1.5 \mathrm{x}} \mathrm{Bi}_{\mathrm{x}} \mathrm{TiO}_{3}$ for charge compensation compared to the size of $\mathrm{Sr}^{2+}$ ions [38].

Figure 3 illustrates the evolution of transmittance spectra of the perovskite Bi-doped ST films deposited on $\mathrm{Al}_{2} \mathrm{O}_{3}$ substrates and analysed in the IR frequency range as a function of temperature from 10 to $300 \mathrm{~K}$ in comparison to that of undoped ST. The spectra of undoped and weakly Bi-doped ST films are rather similar, whereas those of the heavily doped ST film differ significantly, particularly in the low-frequency range. Both undoped and Bi-doped ST films show broad minimum as assigned to TO1 mode. The minimum position shifts to higher frequency with temperature and Bi content increase. A weak second minimum is also observed in the analysed films and as assigned to the TO2 phonon 
response, since an identical mode was reported for the $\mathrm{ST}$ films on $\mathrm{Al}_{2} \mathrm{O}_{3}$ substrates $[18,36]$ and for the ST ceramics at the same frequency of $\sim 176 \mathrm{~cm}^{-1}$ [39]. The asymmetric spectral form of TO2 suggests its coupling to the neighbouring soft mode [18].
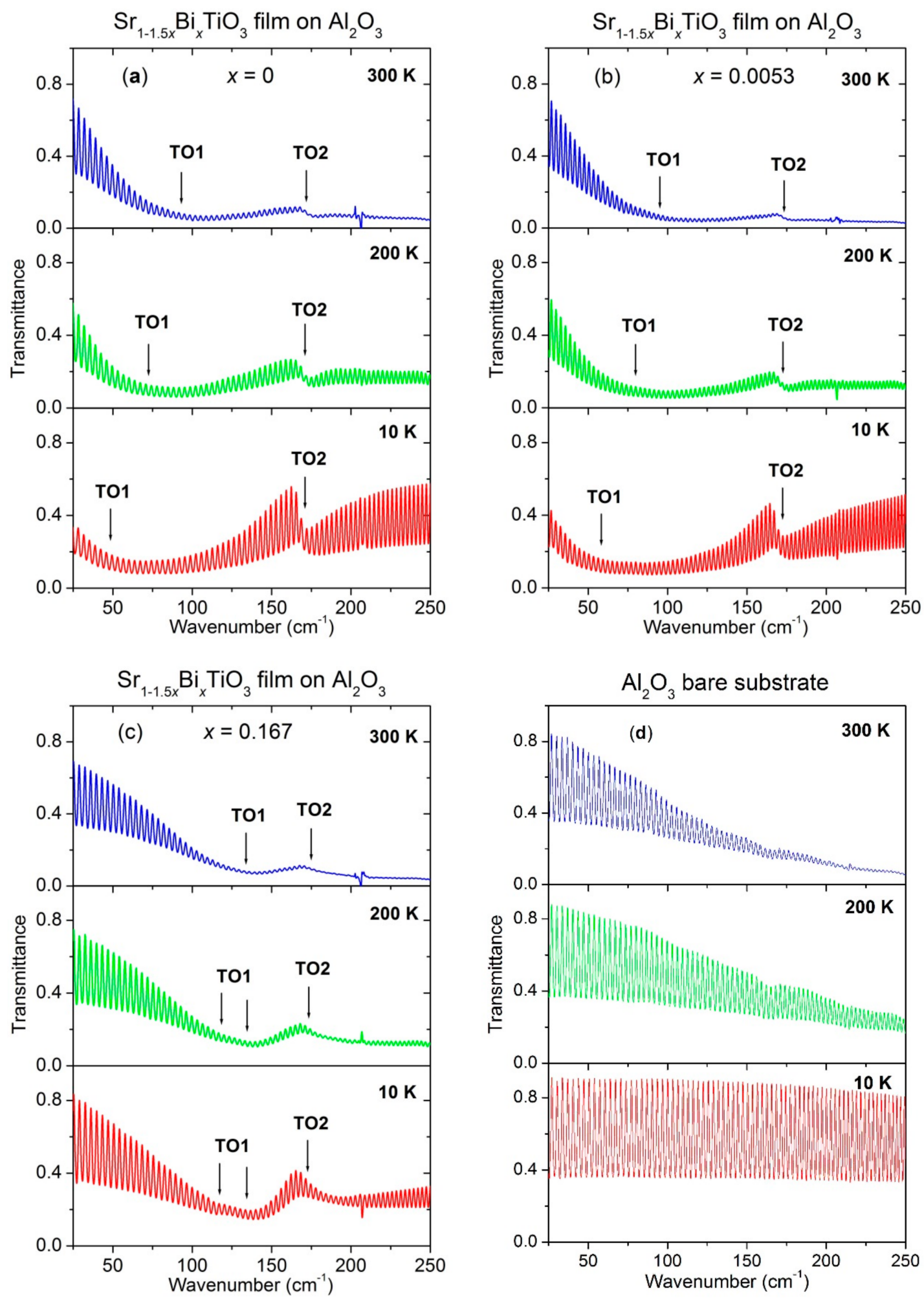

Figure 3. Infrared transmittance spectra at $300 \mathrm{~K}$ (top panel), $200 \mathrm{~K}$ (middle panel) and $10 \mathrm{~K}$ (bottom panel) of $\mathrm{Sr}_{1-1.5 \mathrm{x}} \mathrm{Bi}_{\mathrm{x}} \mathrm{TiO}_{3}$ thin films with $\mathrm{x}=0(\mathbf{a}), 0.0053(\mathbf{b})$ and $0.167(\mathbf{c})$ deposited on $\mathrm{Al}_{2} \mathrm{O}_{3}$ substrates as well as of bare $\mathrm{Al}_{2} \mathrm{O}_{3}$ substrate $(\mathbf{d})$. 
The transmittance spectra of $\mathrm{Sr}_{1-1.5 \mathrm{x}} \mathrm{Bi}_{\mathrm{x}} \mathrm{TiO}_{3}$ films (Figure 3a-c) were fitted to determine the TO mode parameters and to obtain the complex dielectric response function by the classical damped oscillator dispersion model:

$$
\hat{\varepsilon}(\omega)=\varepsilon^{\prime}(\omega)-i \varepsilon^{\prime \prime}(\omega)=\varepsilon(\infty)+\sum_{j=1}^{n} \Delta \varepsilon_{j} \frac{\omega_{T O_{j}}^{2}}{\omega_{T O_{j}}^{2}-\omega^{2}+i \omega \gamma_{T O} O_{j}}
$$

where $\varepsilon(\infty)=n^{2}$ stands for the high-frequency optical permittivity and $\omega_{T O_{j}}, \gamma_{T O_{j}}$ and $\Delta \varepsilon_{j}$ denote the frequency, damping and dielectric strength of the $j$ th transverse optical (TO) phonon mode, respectively. To reduce the ambiguity of the fit, the parameters of the substrate were obtained from an independent fit of the transmittance spectra of a bare substrate (Figure $3 \mathrm{~d}$ ) and then fixed during the subsequent fits of the transmittance spectra of films on the corresponding substrates.

The resulting spectra of the real $\varepsilon^{\prime}$ and imaginary $\varepsilon^{\prime \prime}$ parts of the dielectric permittivity in the IR range shown in Figure 4 present a continuous decrease in the permittivity with increasing Bi content and temperature, reflecting lower polar phonon contribution to the permittivity. Correspondingly, the peak in $\varepsilon^{\prime \prime}$ spectra shifts to a higher frequency and the low-frequency permittivity decreases in agreement with the Lyddane-Sachs-Teller relation [40].
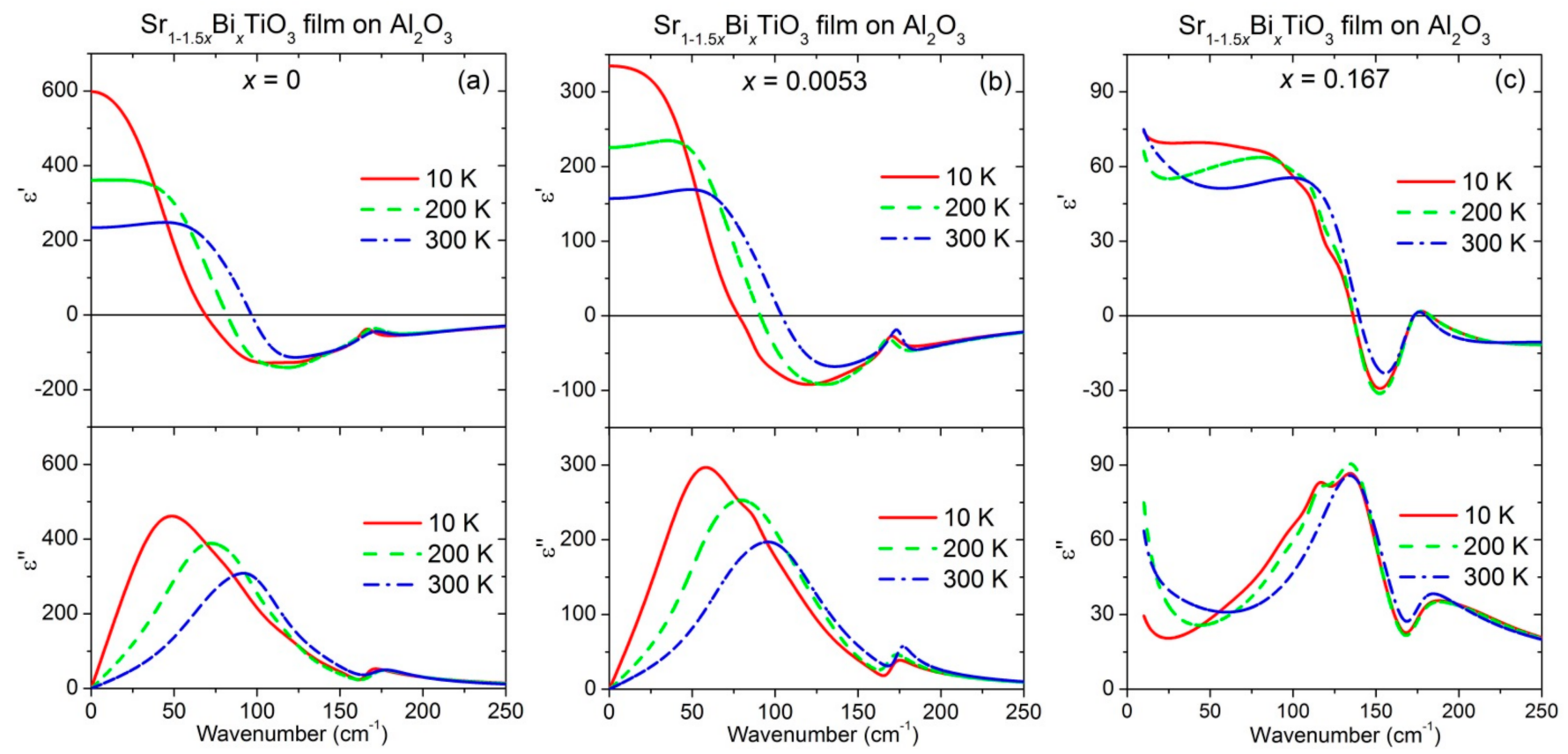

Figure 4. Spectra of the real $\varepsilon^{\prime}$ (top panel) and imaginary $\varepsilon^{\prime \prime}$ (bottom panel) parts of the dielectric permittivity in the infrared range, obtained from the transmittance fits at $10 \mathrm{~K}$ (solid lines), $200 \mathrm{~K}$ (dash lines) and $300 \mathrm{~K}$ (dash-dot lines) for $\mathrm{Sr}_{1-1.5 \mathrm{x}} \mathrm{Bi}_{\mathrm{x}} \mathrm{TiO}_{3}$ thin films with $\mathrm{x}=0$ (a), $0.0053(\mathbf{b})$ and 0.167 (c) deposited on $\mathrm{Al}_{2} \mathrm{O}_{3}$ substrates.

For undoped ST, the $\varepsilon^{\prime \prime}$ peak frequency, corresponding to TO1 mode position, varies from $48 \mathrm{~cm}^{-1}$ at $10 \mathrm{~K}$ to $72 \mathrm{~cm}^{-1}$ at $200 \mathrm{~K}$ and $91 \mathrm{~cm}^{-1}$ at $300 \mathrm{~K}$, as seen in Figure $4 \mathrm{a}$. The same tendency but slightly higher frequency values of $58 \mathrm{~cm}^{-1}$ at $10 \mathrm{~K}, 79 \mathrm{~cm}^{-1}$ at $200 \mathrm{~K}$ and $95 \mathrm{~cm}^{-1}$ at $300 \mathrm{~K}$ can be deduced from Figure $4 \mathrm{~b}$ for $\mathrm{Sr}_{1-1.5 \mathrm{x}} \mathrm{Bi}_{\mathrm{x}} \mathrm{TiO}_{3}$ film with $\mathrm{x}=0.0053$. At the same time, the TO1 mode frequency of Bi-doped ST film with $\mathrm{x}=0.167$ is equal to $\sim 134 \mathrm{~cm}^{-1}$ in the temperature range from $10 \mathrm{~K}$ to $300 \mathrm{~K}$, as shown in Figure 4c.

In addition, weak splitting of the TO1 soft-mode for the $\mathrm{Sr}_{1-1.5 \mathrm{x}} \mathrm{Bi}_{\mathrm{x}} \mathrm{TiO}_{3}$ film with $\mathrm{x}=0.167$ is seen in Figure $4 \mathrm{c}$ below $\sim 200 \mathrm{~K}$. Such a feature, even if not seen in the IR reflectivity of Bi-doped ST ceramics up to $x=0.133$ [27], points to the presence of anisotropic polar clusters around the Bi ions. Moreover, an increase in losses was observed at the 
low-frequency soft-mode wing (below $30 \mathrm{~cm}^{-1}$ ) of $\mathrm{Sr}_{1-1.5 \mathrm{x}} \mathrm{Bi}_{\mathrm{x}} \mathrm{TiO}_{3}$ films with $\mathrm{x}=0.167$ (Figure 4c), not seen in the films with $x=0$ and 0.0053 (Figure 4a,b). Several relaxation regions involving frequency distribution up to the $\mathrm{THz}$ range were reported to appear in the wide-frequency spectra of heavily Bi-doped ST ceramics [27]. These relaxations were related to the reorientation of dipoles created by the off-centred $\mathrm{Bi}^{3+}$ ions (individual hopping of the $\mathrm{Bi}^{3+}$ ions), and to the dynamics of the polar nanoclusters surrounding the $\mathrm{Bi}^{3+}$ ions, which interact with each other via the highly polarisable host crystal lattice (cooperative hopping of the off-centred $\mathrm{Bi}^{3+}$ ions). Therefore, the additional loss increase observed in $\mathrm{Sr}_{1-1.5 \mathrm{x}} \mathrm{Bi}_{\mathrm{x}} \mathrm{TiO}_{3}$ films with $\mathrm{x}=0.167$ at $\sim 10-50 \mathrm{~cm}^{-1}$ (Figure $4 \mathrm{c}$ ) could have the same origin.

The TO1 mode frequency values as a function of temperature are presented in Figure 5 and compared with those reported for undoped and Bi-doped ST ceramics [27,39]. As mentioned above, undoped and weakly Bi-doped ST thin films on $\mathrm{Al}_{2} \mathrm{O}_{3}$ substrates upon cooling display a continuous decrease of the TO1 soft-mode frequency from 91 and $95 \mathrm{~cm}^{-1}$ at $300 \mathrm{~K}$ to 48 and $58 \mathrm{~cm}^{-1}$ at $10 \mathrm{~K}$, respectively. Similar behaviour was reported for undoped and $0.67 \%$ Bi-doped ST ceramics [27,39], as seen in Figure 5 . By contrast, heavily Bi-doped ST ceramics keep the TO1 mode frequency of $134 \mathrm{~cm}^{-1}$ from $10 \mathrm{~K}$ to $300 \mathrm{~K}$ in agreement with the moderate mode frequency variation reported for $13.3 \%$ Bi-doped ST ceramics [27]. Thus, as in the case of Bi-doped ST ceramics, the dielectric relaxations induced by off-centre displacements of the $\mathrm{Bi}^{3+}$ ions on $\mathrm{Sr}$ sites of $\mathrm{Sr}_{1-1.5 \mathrm{x}} \mathrm{Bi}_{\mathrm{x}} \mathrm{TiO}_{3}$ thin films are accompanied by reduced softening of the TO1 mode and absence of the ferroelectric phase transition.

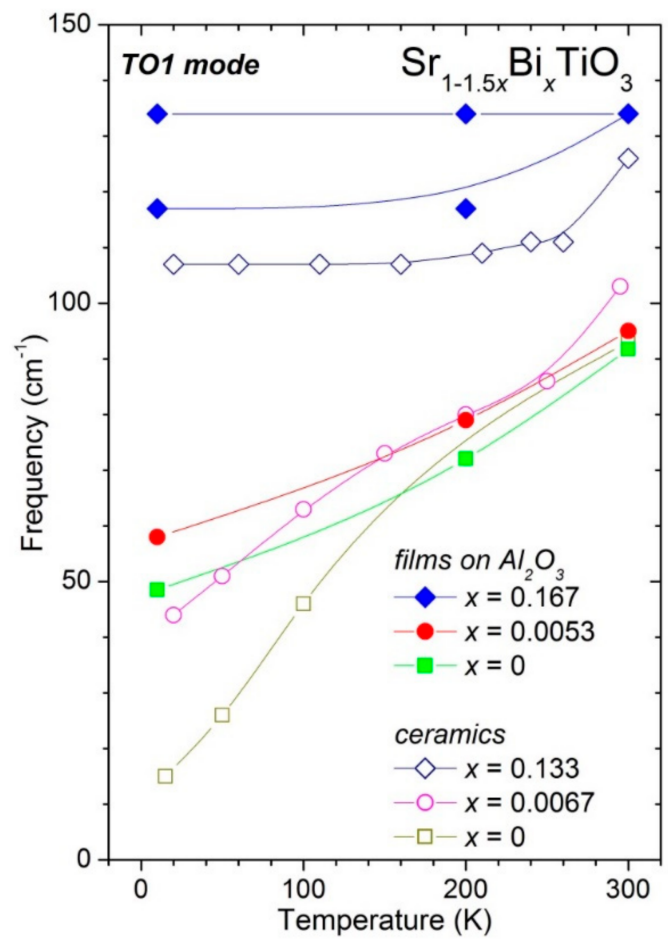

Figure 5. Temperature dependence of the TO1 mode frequency in $\mathrm{Sr}_{1-1.5 \mathrm{x}} \mathrm{Bi}_{\mathrm{x}} \mathrm{TiO}_{3}$ thin films with $\mathrm{x}=0,0.0053$ and 0.167 deposited on $\mathrm{Al}_{2} \mathrm{O}_{3}$ substrates in comparison to that of undoped and Bi-doped ST ceramics with $x=0.0067$ and $0.133[27,39]$. The lines are guides for the eye.

\section{Conclusions}

Bi doping was successfully performed in sol-gel-derived ST thin films deposited on $\mathrm{Al}_{2} \mathrm{O}_{3}$ substrates, as confirmed by EDS and XRD analysis, and found to have a significant effect on their phonon behaviour. In the IR transmittance spectra, the presence of polar Bi off-centring on the cuboctahedral $\mathrm{Sr}$ sites originating in a pronounced dielectric relaxation and the coupling of the resulting electric dipoles to the host lattice is manifested by the 
hardening of the low-frequency TO1 mode relative to the undoped ST. Weakly Bi-doped ST films present soft-mode behaviour, which is only slightly harder than that of undoped ST. Heavily Bi-doped ST films show a high soft-mode frequency without appreciable softening below $300 \mathrm{~K}$. A comparison with Bi-doped ST ceramics, where $\mathrm{Bi}^{3+}$ cations also occupy $\mathrm{Sr}$ sites and exhibit polar displacements, indicates the similarity of such a coupling, yielding dielectric relaxations without triggering a ferroelectric phase transition.

Author Contributions: Conceptualization, P.M.V. and J.P.; methodology, O.O. and D.N.; validation, O.O. and D.N.; formal analysis, O.O., D.N., A.T, J.P. and P.M.V.; investigation, O.O. and D.N.; resources, P.M.V. and J.P.; data curation, O.O. and D.N.; writing-original draft preparation, A.T. and O.O.; writing—review and editing, A.T., O.O., D.N., J.P. and P.M.V.; visualization, A.T. and O.O.; funding acquisition, P.M.V. and J.P. All authors have read and agreed to the published version of the manuscript.

Funding: This article is supported by national funds, through FCT—Fundação para a Ciência e a Tecnologia, in the scope of the framework contract foreseen in numbers 4,5 and 6 of article 23 of the Decree-Law 57/2016, of 29 August, and UID/EMS/00481/2019, UIDB/50011/2020 and UIDP/50011/2020 and by Centro 2020, through the European Regional Development Fund (ERDF), in the scope of the project CENTRO-01-0145-FEDER-022083, by Czech Science Foundation (Project No. 21-06802S) and by the MŠMT Project SOLID21-CZ.02.1.01/0.0/0.0/16_019/0000760).

Institutional Review Board Statement: Not applicable.

Informed Consent Statement: Not applicable.

Data Availability Statement: The data presented in this study are available on request from the corresponding author.

Conflicts of Interest: The authors declare no conflict of interest.

\section{References}

1. Hulm, J.K. The Dielectric Properties of some Alkaline Earth Titanates at Low Temperatures. Proc. Phys. Soc. Sect. A 1950, 63, 1184-1185. [CrossRef]

2. Worlock, J.M.; Fleury, P.A. Electric Field Dependence of Optical-Phonon Frequencies. Phys. Rev. Lett. 1967, 19, 1176-1179. [CrossRef]

3. Müller, K.A.; Burkard, H. SrTiO ${ }_{3}$ : An intrinsic quantum paraelectric below 4 K. Phys. Rev. B 1979, 19, 3593-3602. [CrossRef]

4. Petzelt, J.; Nuzhnyy, D. Soft polar phonon mode in $\mathrm{SrTiO}_{3}$ single crystals, ceramics and thin films. In Strontium Titanate: Synthesis, Properties and Uses; Tkach, A., Vilarinho, P.M., Eds.; Nova Science Publishers: New York, NY, USA, 2019; pp. 1-40.

5. Kleemann, W.; Dec, J.; Tkach, A.; Vilarinho, P.M. SrTiO 3 -glimpses of an inexhaustible source of novel solid state phenomena. Condens. Matter 2020, 5, 58. [CrossRef]

6. Geyer, R.G.; Riddle, B.; Krupka, J.; Boatner, L.A. Microwave dielectric properties of single-crystal quantum paraelectrics $\mathrm{KTaO}_{3}$ and $\mathrm{SrTiO}_{3}$ at cryogenic temperatures. J. Appl. Phys. 2005, 97, 104111. [CrossRef]

7. Tagantsev, A.K.; Sherman, V.; Astafiev, K.; Venkatesh, J.; Setter, N. Ferroelectric Materials for Microwave Tunable Applications. J. Electroceramics 2003, 11, 5-66. [CrossRef]

8. Defaÿ, E.; Wolozan, D.; Blanc, J.-P.; Serret, E.; Garrec, P.; Verrun, S.; Pellissier, D.; Delpech, P.; Guillan, J.; André, B.; et al. High pass filter with above IC integrated $\mathrm{SrTiO}_{3}$ high K MIM capacitors. Solid-State Electron. 2007, 51, 1624-1628. [CrossRef]

9. Servoin, J.L.; Luspin, Y.; Gervais, F. Infrared dispersion in $\mathrm{SrTiO}_{3}$ at high temperature. Phys. Rev. B 1980, 22, 5501-5506. [CrossRef]

10. Axe, J.D.; Harada, J.; Shirane, G. Anomalous Acoustic Dispersion in Centrosymmetric Crystals with Soft Optic Phonons. Phys. Rev. B 1970, 1, 1227-1234. [CrossRef]

11. Vogt, H. Refined treatment of the model of linearly coupled anharmonic oscillators and its application to the temperature dependence of the zone-center soft-mode frequencies of $\mathrm{KTaO}_{3}$ and $\mathrm{SrTiO}_{3}$. Phys. Rev. B 1995, 51, 8046-8059. [CrossRef]

12. Shirane, G.; Yamada, Y. Lattice-Dynamical Study of the $110^{\circ} \mathrm{K}$ Phase Transition in $\mathrm{SrTiO}_{3}$. Phys. Rev. 1969, 177, 858-863. [CrossRef]

13. Rupprecht, G.; Bell, R.O.; Silverman, B.D. Nonlinearity and Microwave Losses in Cubic Strontium-Titanate. Phys. Rev. 1961, 123, 97-98. [CrossRef]

14. Sirenko, A.A.; Akimov, I.A.; Fox, J.R.; Clark, A.M.; Li, H.C.; Si, W.; Xi, X.X. Observation of the first-order Raman scattering in $\mathrm{SrTiO}_{3}$ thin films. Phys. Rev. Lett. 1999, 82, 4500-4503. [CrossRef]

15. Sirenko, A.A.; Akimov, I.A.; Bernhard, C.; Clark, A.M.; Hao, J.-H.; Weidong, S.; Xi, X.X. Lattice dynamical properties of SrTiO 3 thin films. AIP Conf. Proceed. 2000, 535, 201-217. [CrossRef]

16. Sirenko, A.A.; Bernhard, C.; Golnik, A.; Clark, A.M.; Hao, J.; Si, W.; Xi, X.X. Soft-mode hardening in SrTiO 3 thin films. Nature 2000, 404, 373-376. [CrossRef] 
17. Gupta, S.; Katiyar, R.S. Temperature-dependent structural characterization of sol-gel deposited strontium titanate $\left(\mathrm{SrTiO}_{3}\right)$ thin films using Raman spectroscopy. J. Raman Spectrosc. 2001, 32, 885-891. [CrossRef]

18. Ostapchuk, T.; Petzelt, J.; Zelezny, V.; Pashkin, A.; Pokorny, J.; Drbohlav, I.; Kuzel, R.; Rafaja, D.; Gorshunov, B.P.; Dressel, M.; et al. Origin of soft-mode stiffening and reduced dielectric response in $\mathrm{SrTiO}_{3}$ thin films. Phys. Rev. B 2002, 66, 235406. [CrossRef]

19. Nuzhnyy, D.; Petzelt, J.; Kamba, S.; Yamada, T.; Tyunina, M.; Tagantsev, A.K.; Levoska, J.; Setter, N. Polar phonons in some compressively stressed epitaxial and polycrystalline $\mathrm{SrTiO}_{3}$ thin films. J. Electroceramics 2008, 22, 297-301. [CrossRef]

20. Fleury, P.A.; Worlock, J.M. Electric-Field-Induced Raman Scattering in $\mathrm{SrTiO}_{3}$ and $\mathrm{KTaO}_{3}$. Phys. Rev. 1968, 174, 613-623. [CrossRef]

21. Okhay, O.; Tkach, A.; Vilarinho, P.M. Effect of bismuth doping on the properties of strontium titanate thin films. In Strontium Titanate: Synthesis, Properties and Uses; Tkach, A., Vilarinho, P.M., Eds.; Nova Science Publishers: New York, NY, USA, 2019; pp. 209-257.

22. Tkach, A.; Okhay, O. Comment on "Hole-pinned defect-dipoles induced colossal permittivity in $\mathrm{Bi}_{\text {doped }} \mathrm{SrTiO}_{3}$ ceramics with Sr deficiency". J. Mater. Sci. Technol. 2020, 65, 151-153. [CrossRef]

23. Wang, H.; Zhang, W.; Xu, J.; Liu, G.; Xie, H.; Yang, L. Resistance-switching properties of Bi-doped SrTiO 3 films for non-volatile memory applications with different device structures. Bull. Mater. Sci. 2018, 41, 149. [CrossRef]

24. Chen, C.; Bousnina, M.; Giovannelli, F.; Delorme, F. Influence of Bi on the thermoelectric properties of SrTiO $3-\delta$. J. Materiomics 2018, 5, 88-93. [CrossRef]

25. Skanavi, G.I.; Ksendzov, I.J.; Trigubenko, V.A.; Prokhvatilov, V.G. Relaxation polarization and losses in nonferroelectric dielectrics with high dielectric constants. Sov. Phys. JETP 1958, 6, 250-259.

26. Ang, C.; Yu, Z. Dielectric relaxor and ferroelectric relaxor: Bi-doped paraelectric SrTiO 3 . J. Appl. Phys. 2002, 91, 1487-1494. [CrossRef]

27. Porokhonskyy, V.; Pashkin, A.; Bovtun, V.; Petzelt, J.; Savinov, M.; Samoukhina, P.; Ostapchuk, T.; Pokorny, J.; Avdeev, M.; Kholkin, A.; et al. Broad-band dielectric spectroscopy of $\mathrm{SrTiO}_{3}$ :Bi ceramics. Phys. Rev. B 2004, 69, 144104. [CrossRef]

28. Okhay, O.; Wu, A.; Vilarinho, P.M.; Tkach, A. Dielectric relaxation of $\mathrm{Sr}_{1-1.5 x} \mathrm{Bi}_{\mathrm{x}} \mathrm{TiO}_{3}$ sol-gel thin films. J. Appl. Phys. 2011, 109, 064103. [CrossRef]

29. Okhay, O.; Bergano, V.M.; Wu, A.Y.; Vilarinho, P.M. Bi Effect on the Microstructure and Dielectric Properties of $\mathrm{SrTiO}_{3} \mathrm{Thin}_{\mathrm{Films}}$ Mater. Sci. Forum 2006, 514-516, 245-249. [CrossRef]

30. Zhao, M.; Yao, X.; Shi, P.; Wei, X.; Wu, X.; Ren, W.; Lin, P. Effect of poly(vinyl acetate) on structure and property of bismuth-doped strontium titanate thin films derived by sol-gel method. Ceram. Int. 2008, 34, 997-1001. [CrossRef]

31. Shi, P.; Ren, W.; Zhao, M.; Wei, X.; Wu, X.; Chen, X.; Yao, X. Structure and dielectric properties of $\left(\mathrm{Sr}_{1-1.5 \mathrm{x}} \mathrm{Bi}_{\mathrm{x}}\right) \mathrm{TiO}_{3}$ thin films. J. Appl. Phys. 2009, 105, 084104. [CrossRef]

32. Okhay, O.; Wu, A.; Vilarinho, P.M.; Tkach, A. Dielectric response of polycrystalline $\mathrm{Sr}_{1-1.5 \mathrm{x}} \mathrm{Bi}_{\mathrm{x}} \mathrm{TiO}_{3}$ thin films under direct current bias. Appl. Phys. Lett. 2010, 97, 062912. [CrossRef]

33. Song, B.; Wu, S.; Li, F.; Chen, P.; Shen, B.; Zhai, J. Excellent energy storage density and charge-discharge performance in a novel $\mathrm{Bi}_{0.2} \mathrm{Sr}_{0.7} \mathrm{TiO}_{3}-\mathrm{BiFeO}_{3}$ thin film. J. Mater. Chem. C 2019, 7, 10891-10900. [CrossRef]

34. Liu, Y.; Yao, M.; Yao, X. Enhancement of energy storage density achieved in Bi-modified $\mathrm{SrTiO}_{3}$ thin films by introducing a TiO 2 layer. J. Alloys Compd. 2021, 882, 160668. [CrossRef]

35. Fedorov, I.; Železny, V.; Petzelt, J.; Trepakov, V.; Jelinek, M.; Trtík, V.; Čerňansky, M.; Studnička, V. Far-infrared spectroscopy of a $\mathrm{SrTiO}_{3}$ thin film. Ferroelectrics 1998, 208-209, 413-427. [CrossRef]

36. Okhay, O.; Tkach, A.; Nuzhnyy, D.; Petzelt, J.; Vilarinho, P.M. Polar phonons in polycrystalline $\mathrm{SrTiO}_{3}$ thin films: The role of the substrate. Ferroelectrics 2018, 532, 89-99. [CrossRef]

37. Yu, Z.; Ang, C.; Vilarinho, P.M.; Mantas, P.Q.; Baptista, J.L. Dielectric relaxation behaviour of Bi: SrTiO 3 : I. The low temperature permittivity peak. J. Eur. Ceram. Soc. 1998, 18, 1613-1619. [CrossRef]

38. Tkach, A.; Almeida, A.; Moreira, J.A.; Correia, T.M.; Chaves, M.R.; Okhay, O.; Vilarinho, P.; Gregora, I.; Petzelt, J. Enhancement of tetragonality and role of strontium vacancies in heterovalent doped $\mathrm{SrTiO}_{3}$. Appl. Phys. Lett. 2011, 98, 052903. [CrossRef]

39. Petzelt, J.; Ostapchuk, T.; Gregora, I.; Rychetsky, I.; Hoffmann-Eifert, S.; Pronin, A.V.; Yuzyuk, Y.; Gorshunov, B.P.; Kamba, S.; Bovtun, V.; et al. Dielectric, infrared, and Raman response of undoped $\mathrm{SrTiO}_{3}$ ceramics: Evidence of polar grain boundaries. Phys. Rev. B 2001, 64, 184111. [CrossRef]

40. Lyddane, R.H.; Sachs, R.G.; Teller, E. On the Polar Vibrations of Alkali Halides. Phys. Rev. 1941, 59, 673-676. [CrossRef] 